pISSN : 1979-0694

\title{
APLIKASI E-SURVEY BERBASIS WEB PADA STMIK DUMAI
}

\author{
Nasrul Naim ${ }^{1}$, Ridarmin ${ }^{2}$, Pulla Pandika Widodo ${ }^{3}$ \\ ${ }^{1,2}$ Sekolah Tinggi Manajemen Informatika Dan Komputer ( STMIK ) Dumai \\ Jln. Utama Karya Bukit Batrem Dumai-Riau Kode Pos 28811 \\ Email : ridarmin@mail.stmikdumai.ac.id ${ }^{2}$
}

\begin{abstract}
ABSTRAK
Telah dilakukan Penelitian pada STMIK Dumai, dimana permasalahan yang dijadikan dasar dalam penulisan skripsi ini yaitu membuat aplikasi yang dapat memudahkan pengguna untuk mahasiswa melakukan e-survey terhadap pelayanan kampus STMIK Dumai. Oleh karena itu, dirancang sebuah aplikasi yang dapat memudah pengguna untuk melakukan survey. Dengan adanya Aplikasi E-Survey Berbasis Web ini, maka memudahkan mahasiswa untuk melakukan survey terhadap pelayanan kampus STMIK Dumai sudah dilakukan terkomputerisasi dan online.
\end{abstract}

Kata Kunci : E-Survey, Aplikasi, Web, Pelayanan

\section{PENDAHULUAN}

Komputer saat ini merupakan kebutuhan manusia di dalam melakukan berbagai kegiatan, ditambah dengan adanya teknologi informasi yang semakin berperan di dalam dunia pekerjaan dengan menggunakan piranti teknologi informasi yang tepat, maka akan dihasilkan informasi yang tepat dan akurat sesuai dengan kebutuhan sehingga keputusan dapat diambil dengan cepat.

Sebagai contoh lembaga survey berbasis Elektronik Sistem Survey Unsera (E-Survey) adalah sistem survey online berbasis web yang terintegrasi langsung antar jaringan/network Client-Server dengan akses LAN, WAN dan Internet. ${ }^{1} \quad$ Survey yang dilakukan dalam melakukan penelitian biasanya dilakukan dengan menyebarkan kuesioner atau wawancara, dengan tujuan untuk mengetahui siapa mereka, apa yang mereka pikir, rasakan atau kecenderungan suatu tindakan. Survey lazim dilakukan dalam penelitian kuantitatif maupun kualitatif.

Dalam survey, informasi dikumpulkan dari responden melalui kuesioner. Umumnya pengertian survey dibatasi pada penelitian dengan

\footnotetext{
${ }^{1} \mathrm{http}: / / w w w . e s u r v e y . u n s e r a . a c . i d$
}

data yang dikumpulkan dari sampel untuk mewakili seluruh populasi. Ini berbeda dengan sensus yang informasinya dikumpulkan dari seluruh populasi. Dengan demikian, penelitian survei adalah penelitian yang mengambil sampel dari suatu populasi dan menggunakan kuesioner sebagai alat pengumpulan data yang pokok. (Sofian effendi, dkk. 2012:3).

STMIK sebagai salah satu perguruan tinggi swasta yang ada di kota Dumai dengan 2 (dua) program studi yaitu: Sistem Informasi dan Teknik Informatika. Sebagai institusi pendidikan yang bergerak dibidang keilmuan komputer, menjadi suatu keharusan akan penggunaan sistem terkomputerisasi. Pemakaian komputer sebagai alat pengolah data dapat dikatakan yang terbaik saat ini, karena dapat meningkatkan kecepatan pekerjaan sehingga dicapai efisiensi tenaga dan waktu mengolah data. Salah satu kebutuhan yang terkomputerisasi di STMIK- Dumai adalah Aplikasi E-Survey Berbasis Web Pada STMIK Dumai yang akan diterapkan untuk meningkatkan layanan kampus.

Namun aplikasi E-Survey Berbasis Web pada STMIK Dumai belum ada, masih menggunakan selebaran kertas. Dimana penggunaan pada proses survey masih menggunakan pulpen dan kertas 
secara manual dalam melakukan kuesioner terhadap pelayanan pada kampus oleh setiap mahasiswa untuk memberikan masukan, saran maupun kritik untuk pelayanan dilingkungan STMIK Dumai. bagi setiap mahasiswa pun harus mengisi beberapa kuesioner dengan mengisi kertas yang disediakan oleh pihak kampus yang masih manual.

Menurut Sofian Effendi, dkk. (2012 : 30) Dalam penelitian sosial, metode survei telah mengalami perkembangan yang sangat pesat dan telah memiliki ciri-ciri metode penelitian yang sangat pesat dan telah memiliki ciri-ciri metode penelitian yang mandiri. kekhususan metode penelitian tersebut terlihat dari proses penyusunan kerangka teori, tujuan penelitian, penggunaan survei sebagai prosedur dan teknik pengumpulan data, serta analisis data yang membedakan metode tersebut dengan metode penelitian sosial lainnya.

Seperti yang telah dijelaskan sebelumnya diatas, penelitian survei terdiri atas dua tahap, yakni tahap teoretisasi dan tahap empirisasi. Agar dapat melaksanakan penelitian dengan baik, penelitian harus memiliki pengetahuan tentang berbagai unsur penelitian. Dalam proses teoretisasi pemahaman penelitian tentang konsep, proposisi, dan teori akan memungkinkannya merumuskan fenomena sosial sebagai hubunganhubungan teoretis dengan jelas.

Kemampuan, daya imajinasi, dan kreativitas seorang peneliti akan sangat ditentukan oleh perbendaharaan konsep, proposisi, dan teori dalam disiplinya sendiri. Pada tahap empirisasi pengetahuan tentang variabel, hipotesis, dan definisi operasional sangat menentukan kemampuan peneliti dalam mengonstruksikan masalah penelitian yang biasanya berupa fenomena sosial atau fenomena natural yang menarik perhatiannya. Peneliti juga mendapat gambaran tentang apa dan bagaimana cara mengumpulkan data yang diperlukannya dalam suatu penelitian.

\section{METODOLOGI PENELITIAN}

Adapun metode penelitian yang dilakukan penulis dalam skripsi ini adalah sebagai berikut :

1) Waktu dan tempat penelitian

a. Waktu

Penelitian dilakukan mulai dari Juni 2016 sampai dengan Juli

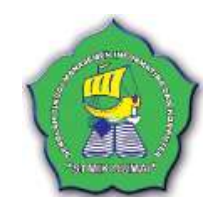

2017 atau disesuai dengan tenggang waktu yang diberikan oleh pihak kampus.

b. Tempat Penelitian

Penelitian dilakukan di STMIK

Dumai sesuai dengan pesetujuan

yang diberikan oleh Pihak Kampus STMIK Dumai.

2) Field Research (Penelitian Lapangan)

Yaitu melakukan penelitian langsung pada objek pembahasan yaitu pada Kampus STMIK Dumai dengan tujuan mendapatkan informasi yang benar dan akurat.

a. Wawancara atau Interview

Yaitu pengumpulan data dengan mengajukan pertanyaan langsung kepada pihak yang berhubungan dengan informasi yang dibutuhkan.

b. Observasi

Yaitu pengamatan langsung kepada objek yang akan diteliti, dilakukan dalam waktu yang singkat, observasi bertujuan untuk mengecek sendiri kebenaran data informasi yang telah dikumpulkan.

3) Library Research (Penelitian Perpustakaan)

Yaitu penelitian kepustakaan adalah usaha mengumpulkan keterangan melalui bahan yang ditulis, selain memperoleh data dan informasi yang dibutuhkan, penelitian ini juga didukung dengan referensi bukubuku, internet yang berkaitan dengan analisis dan perancangan sistem informasi agar data yang didapatkan bisa dijadikan acuan untuk menyeleksi permasalahan agar dapat diketahui dengan benar. 
I N F O R M A T I A Jurnal Informatika, Manajemen dan Komputer, Vol. 8 No. 2 , Desember 2016 eISSN : 2580-3042

pISSN : 1979-0694

3. HASIL DAN PEMBAHASAN

a. Analisa Sistem Berjalan

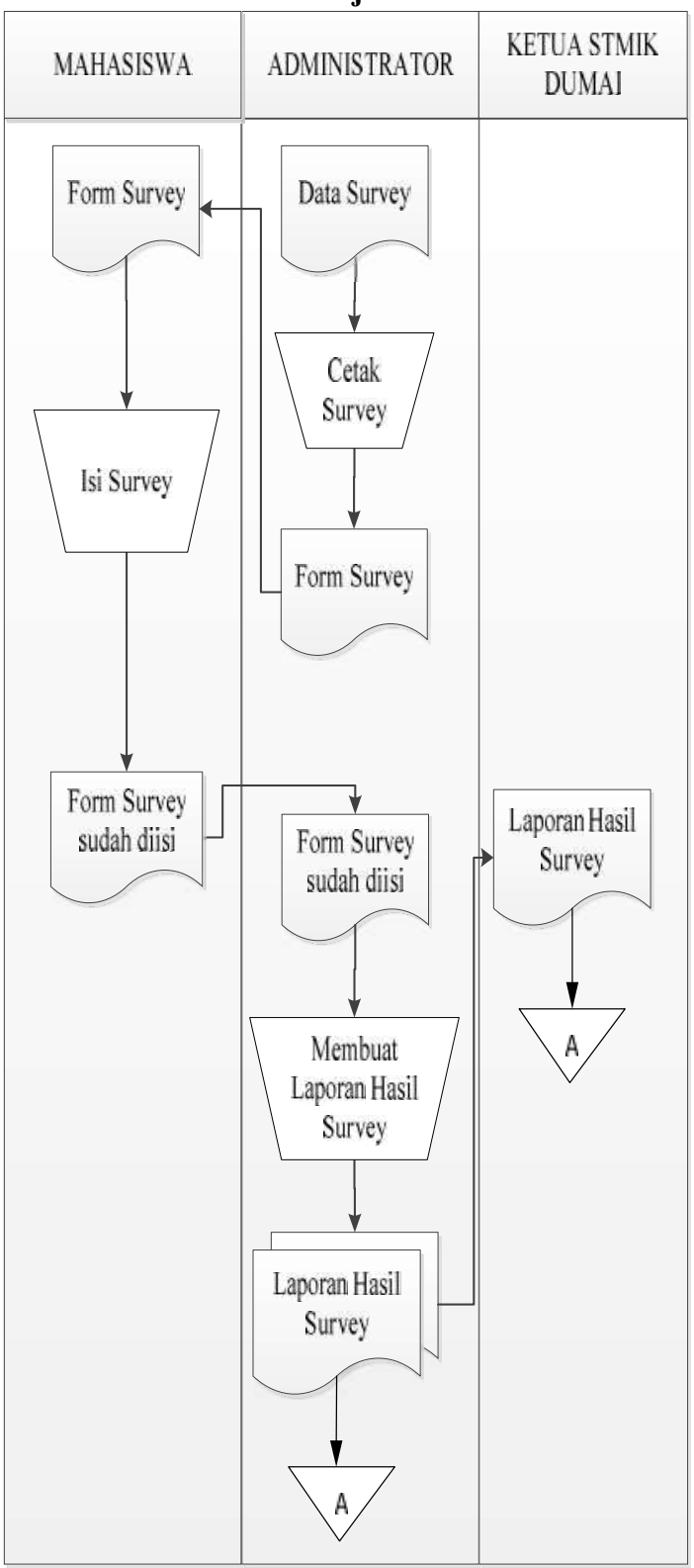

Gambar 1. ASI Berjalan

Keterangan :

1. Admin membuat catatan survey kemudian mencetaknya menjadi form survey.

2. Admin memberikan form survey tersebut kepada mahasiswa untuk diisi.

3. Setelah selesai mengisi form survey, mahasiswa menyerahkannya kembali ke admin.

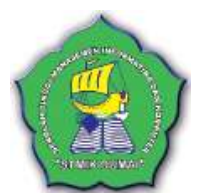

4. Setelah semua form survey terkumpul, petugas membuat laporan hasil survey.

5. Admin menyerahkan laporan hasil survey kepada Ketua STMIK Dumai.

\section{b. Analisa Sistem Yang Baru}

Adapun aliran sistem baru dapat dilihat pada gambar 2 sebagai berikut :

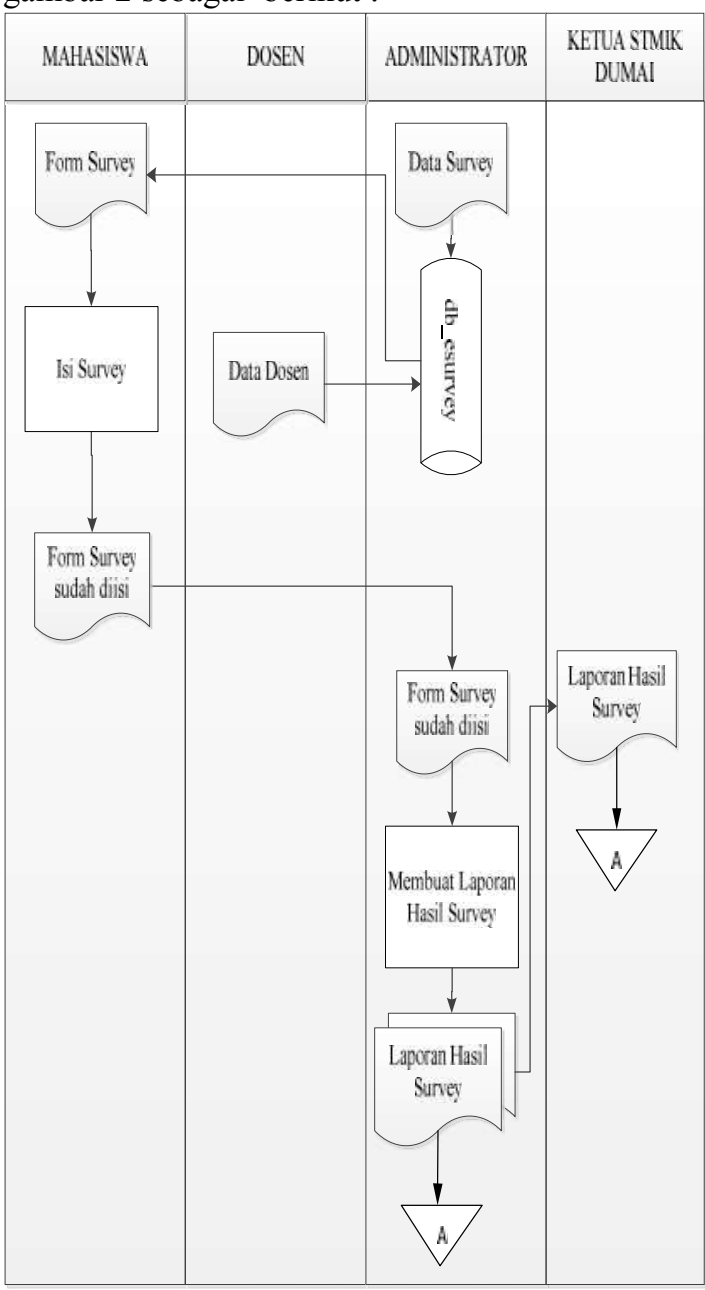

Gambar 2. ASI Baru

Keterangan :

1. Admin menginput data survey ke dalam aplikasi.

2. Mahasiswa mengakses form survey melalui aplikasi.

3. Mahasiswa mengisi form survey dan menyimpan data.

4. Admin mengakses dan mencetak laporan hasil survey.

5. Admin menyerahkan laporan hasil survey kepada Ketua STMIK Dumai. 


\section{c. Context Diagram}

Adapun context diagram dapat digambarkan seperti pada gambar 3 dibawah ini :

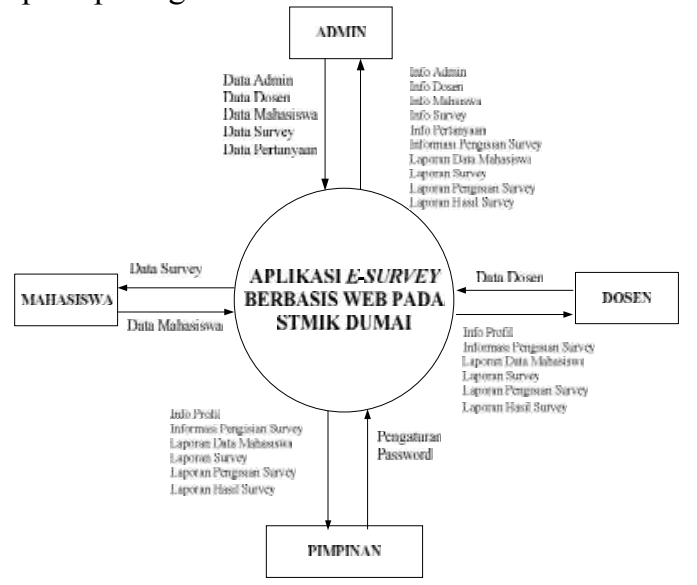

Gambar 3. Context Diagram

Keterangan :

Ada 4 pengguna yang dapat mengakses aplikasi survey ini. Admin membuat data admin, dosen, mahasiswa, dan survey. Dosen memperbaharui profilnya, dan mahasiswa mengakses dan melakukan pengisian survey. Beberapa laporan yaitu : laporan data mahasiswa, laporan data survey, dan laporan hasil survey.

\section{d. Data Flow Diagram}

Adapun data flow diagram dapat digambarkan seperti pada gambar 10 dibawah ini :

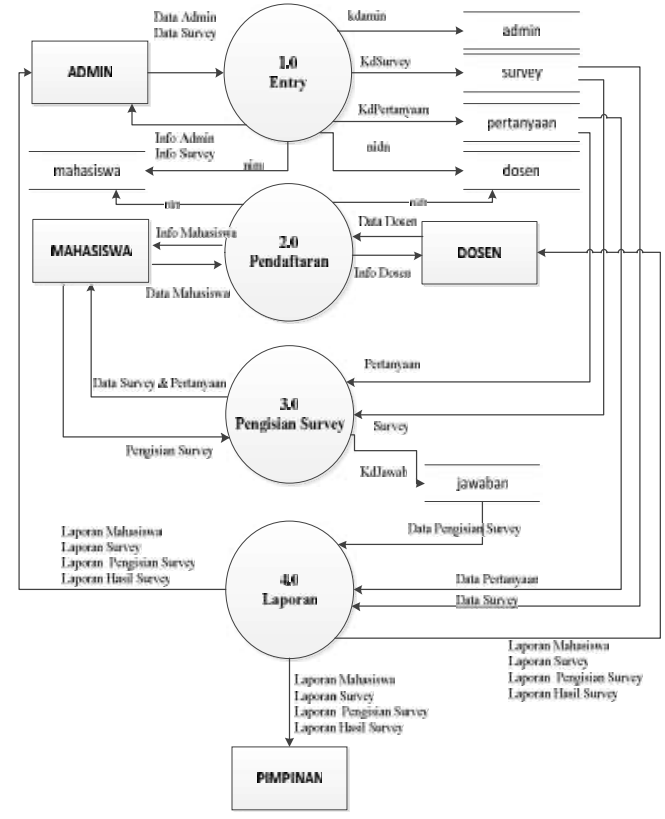

Gambar 4. Data Flow Diagram Level 1
Keterangan :

Pada Aplikasi Survey ini, membutuhkan database dengan tabel-tabel seperti : tabel admin, tabel mahasiswa, tabel dosen, tabel survey, tabel pertanyaan, tabel jawaban, dan tabel logsurvey.

\section{e. Implementasi Sistem}

Adapun halaman login Aplikasi E-Survey ini adalah sebagai berikut:

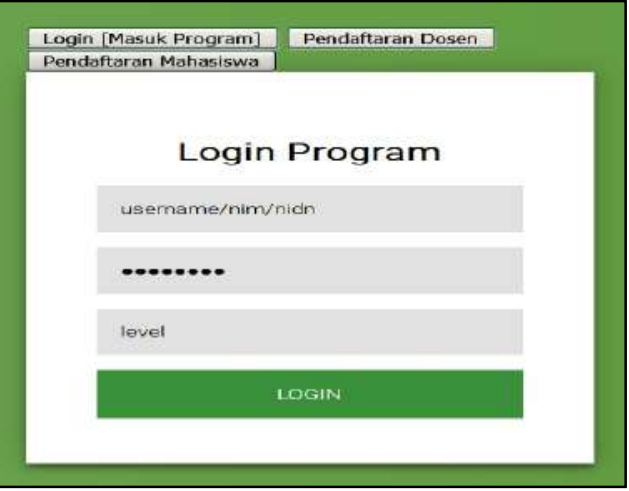

Gambar 5. Halaman Log In aplikasi E-Survey lain :

Pada gambar diatas terdapat 3 pilihan antara

\section{Login [Masuk Program]}

Pilihan ini adalah akses untuk melakukan login bagi administrator, mahasiswa/dosen, atau pimpinan. Dibawah ini adalah gambar form login :

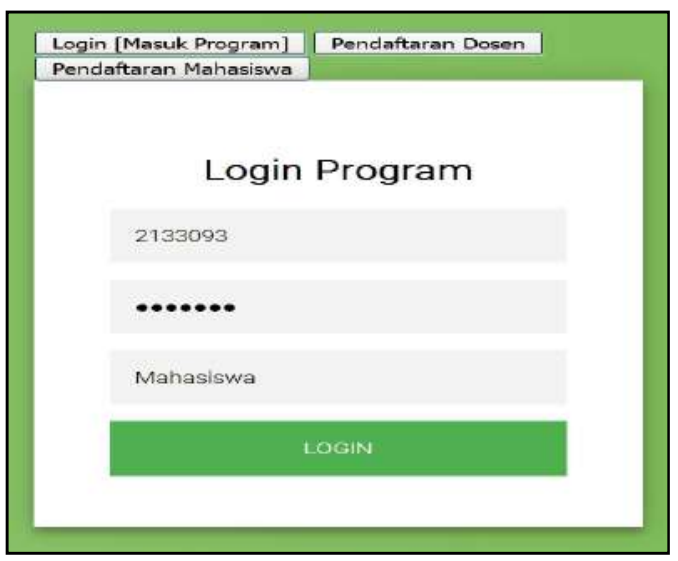

Gambar 6. Tampilan Form Login

\section{Pendaftaran Dosen}

Pilihan ini adalah akses bagi dosen untuk mendaftar sebagai pengguna di aplikasi E-Survey. Berikut gambar form pendaftaran dosen : 
I N F O R M A T I A Jurnal Informatika, Manajemen dan Komputer, Vol. 8 No. 2 , Desember 2016 eISSN : 2580-3042

pISSN : 1979-0694

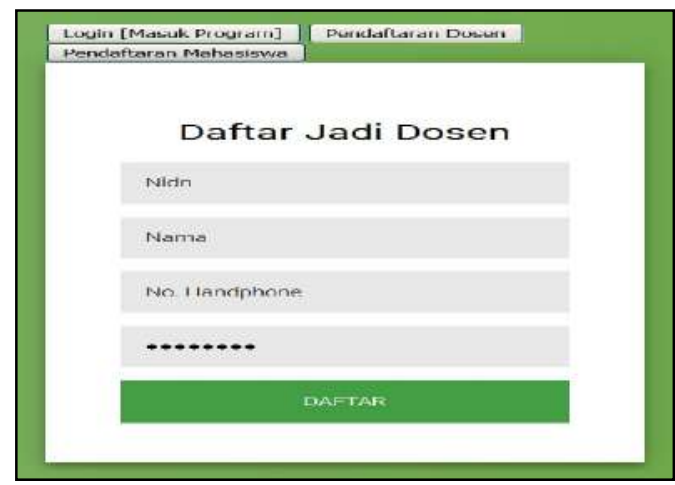

Gambar 7. Form Pendaftaran Dosen

\section{Pendaftaran Mahasiswa}

Pilihan ini adalah akses bagi mahasiswa untuk mendaftar sebagai pengguna di aplikasi $E$ Survey. Berikut adalah gambar dari form pendaftaran mahasiswa.

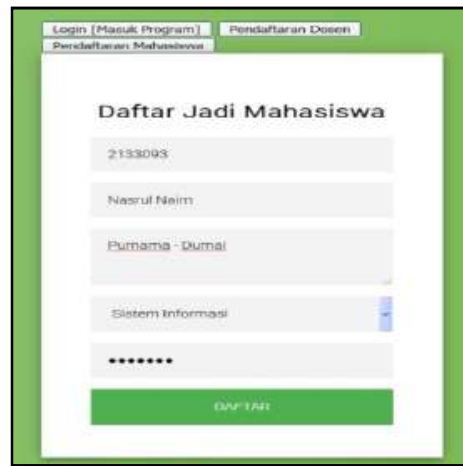

Gambar 8. Form Pendaftaran Mahasiswa

\section{Administrator}

Adapun halaman utama administrator adalah seperti gambar di bawah ini :

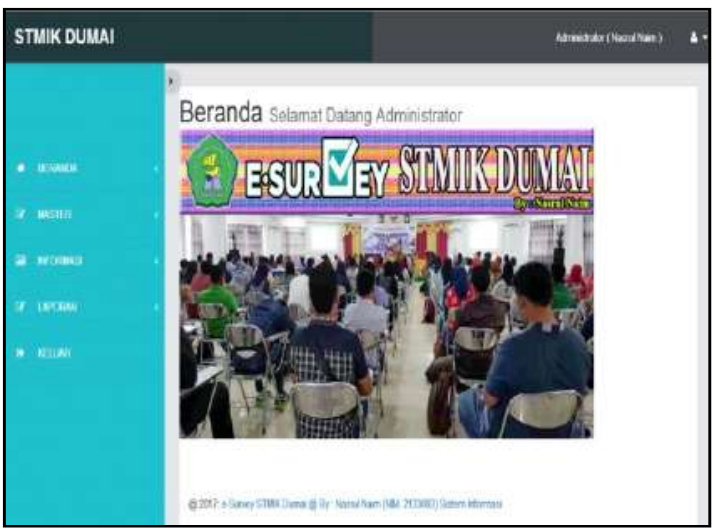

Gambar 9. Halaman Utama Administrator

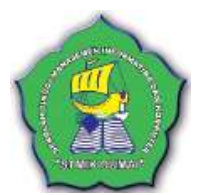

Pada kolom yang terletak di sebelah kiri terdiri dari beberapa menu utama antara lain :

1. Beranda

Menu beranda ini adalah halaman utama administrator.

2. Master

Pada Menu Master terbagi lagi menjadi beberapa submenu yaitu :

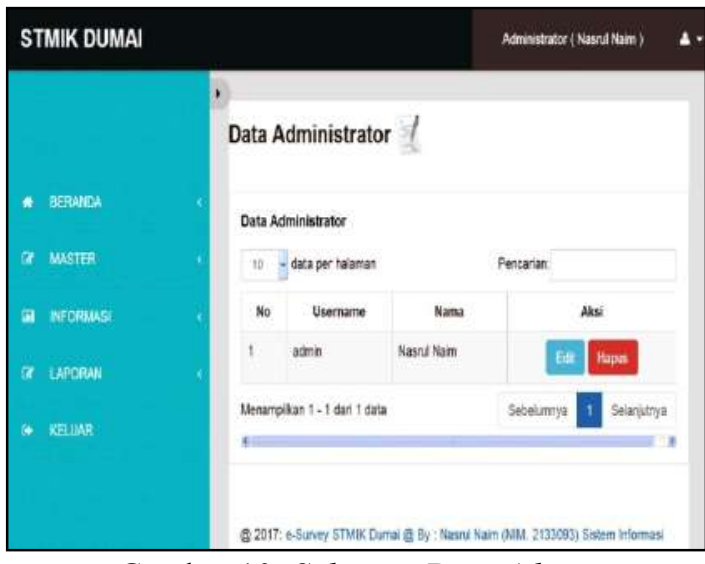

Gambar 10. Submenu Data Admin

Pada submenu ini, administrator akan mengolah data administrator. Data administrator lebih dari 1 , hal ini untuk mengantisipasi password atau username yang terlupa. Untuk menambah data administrator, dapat dengan mengklik gambar<smiles>[CH]1[CH]CC1</smiles>

(tambah data baru) yang ada diatas tabel. Untuk mensunting data administrator dapat dengan mengklik tombol (edit). Untuk menghapus data administrator dapat dengan mengklik tombol (hapus).

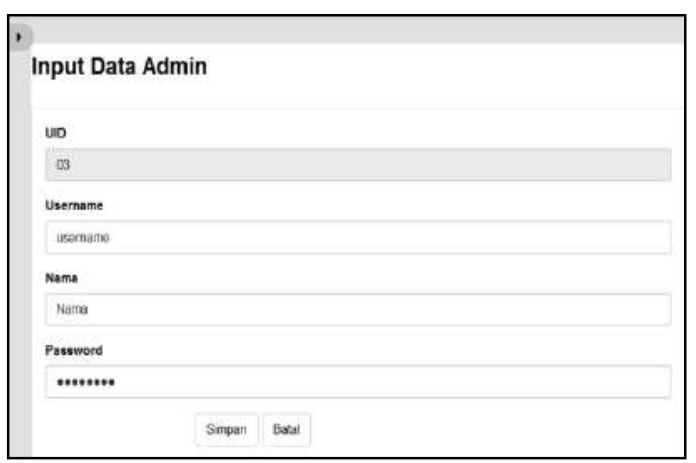

Gambar 11. Halaman Input Data Administrator 
I N F O R M A T I A Jurnal Informatika, Manajemen dan Komputer, Vol. 8 No. 2 , Desember 2016 eISSN : 2580-3042

pISSN : 1979-0694

Pada form input data administrator ini, wajib untuk mengisi seluruh kolom teks. Untuk menyimpan data klik tombol Simpan. Lalu untuk membatalkan proses klik tombol Batal.

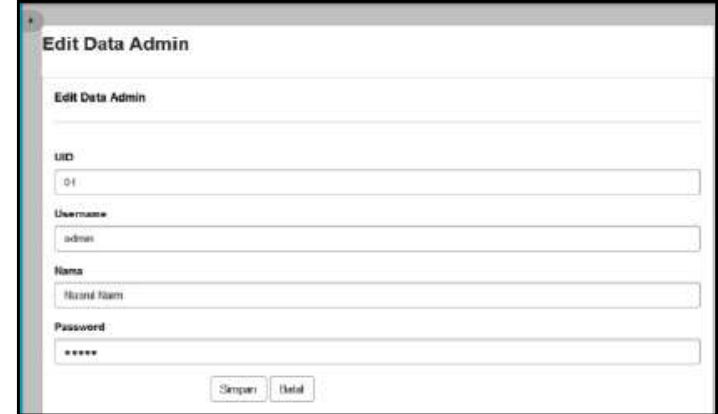

Gambar 12. Halaman Edit Data Administrator.

Pada halaman edit data administrator ini, semua kolom wajib diisi kecuali kolom teks password, hal ini dimaksudkan apabila admin tidak ingin mengubah password yang lama. Untuk menyimpan data klik tombol Simpan. Lalu untuk membatalkan proses klik tombol Batal.

\section{Data Dosen}

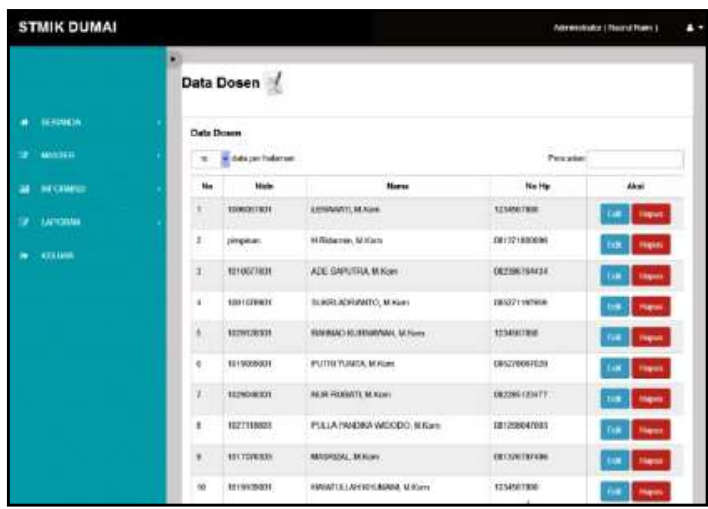

Gambar 13. Submenu Data Dosen

Pada submenu ini, administrator akan mengolah data dosen. Untuk menambah data

dosen, dapat dengan mengklik gambar (tambah data baru) yang ada diatas tabel. Untuk mensunting data dosen dapat dengan mengklik tombol (edit). Untuk menghapus data dosen dapat dengan mengklik tombol (hapus).

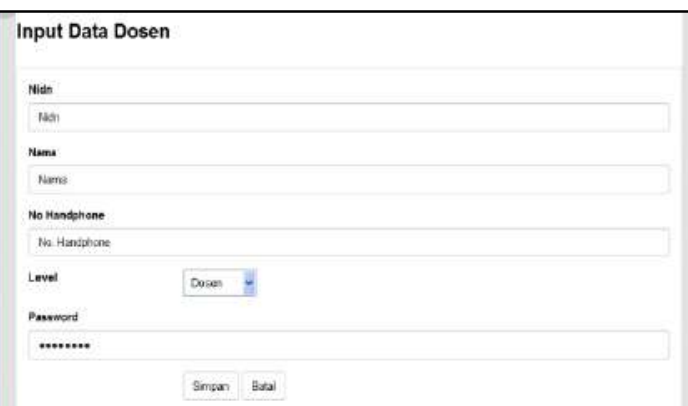

Gambar 14. Halaman Input Data Dosen

Pada form input data dosen ini, wajib untuk mengisi seluruh kolom teks. Untuk menyimpan data klik tombol Simpan. Lalu untuk membatalkan proses klik tombol Batal.

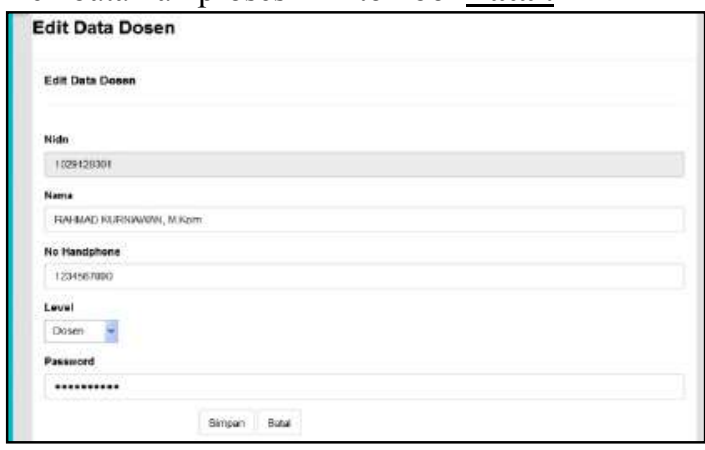

Gambar 15. Halaman Edit Data Dosen.

Pada halaman edit data dosen ini, semua kolom wajib diisi kecuali kolom teks password, hal ini dimaksudkan apabila pengguna tidak ingin mengubah password yang lama. Untuk menyimpan data klik tombol Simpan. Lalu untuk membatalkan proses klik tombol Batal.

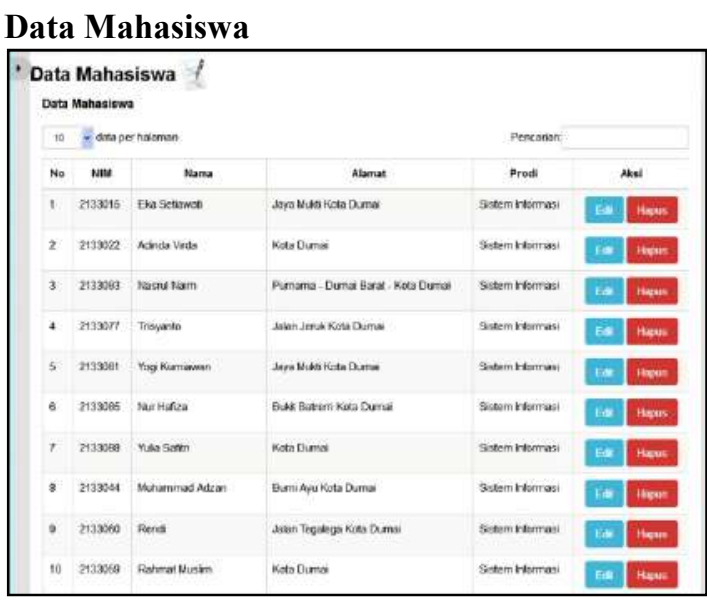

Gambar 16. Submenu Data Mahasiswa 
Pada submenu ini, administrator akan mengolah data mahasiswa. Untuk menambah data

mahasiswa, dapat dengan mengklik gambar (tambah data baru) yang ada diatas tabel. Untuk mensunting data mahasiswa dapat dengan mengklik tombol (edit). Untuk menghapus data mahasiswa dapat dengan mengklik tombol

Hagi:

(hapus).

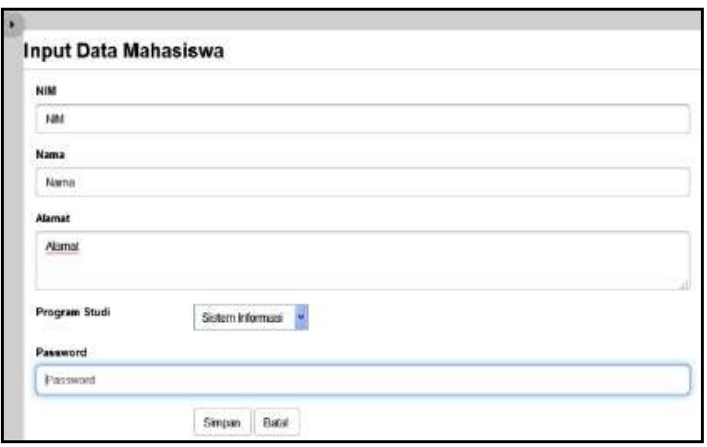

Gambar 17. Halaman Input Data Mahasiswa

Pada form input data mahasiswa ini, wajib untuk mengisi seluruh kolom teks. Untuk menyimpan data klik tombol Simpan. Lalu untuk membatalkan proses klik tombol Batal.

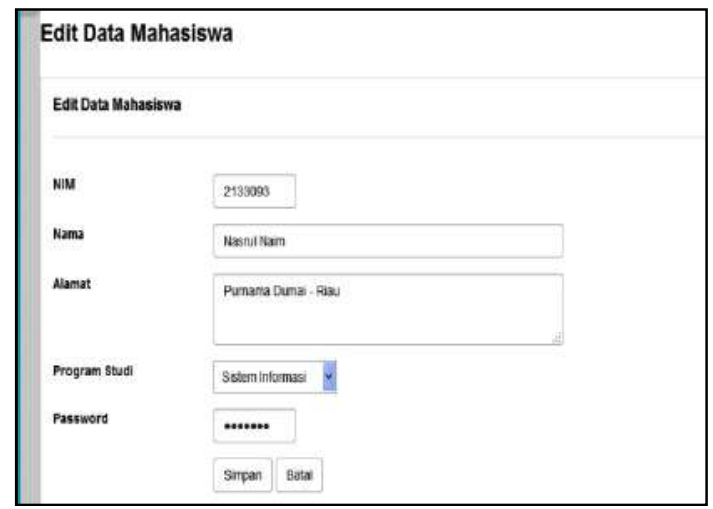

Gambar 18. Halaman Edit Data Mahasiswa

Pada halaman edit data mahasiswa ini, semua kolom wajib diisi kecuali kolom teks password, hal ini dimaksudkan apabila pengguna tidak ingin mengubah password yang lama. Untuk menyimpan data klik tombol Simpan. Lalu untuk membatalkan proses klik tombol Batal.
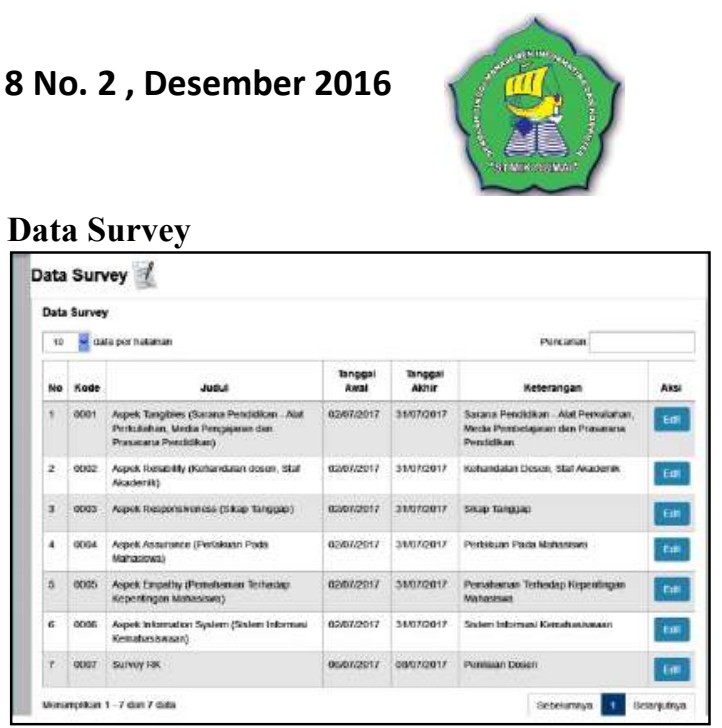

Gambar 19. Submenu Data Survey

Pada submenu ini, administrator akan mengolah data survey. Untuk menambah data

survey, dapat dengan mengklik gambar (tambah data baru) yang ada diatas tabel. Untuk mensunting data survey dapat dengan mengklik tombol

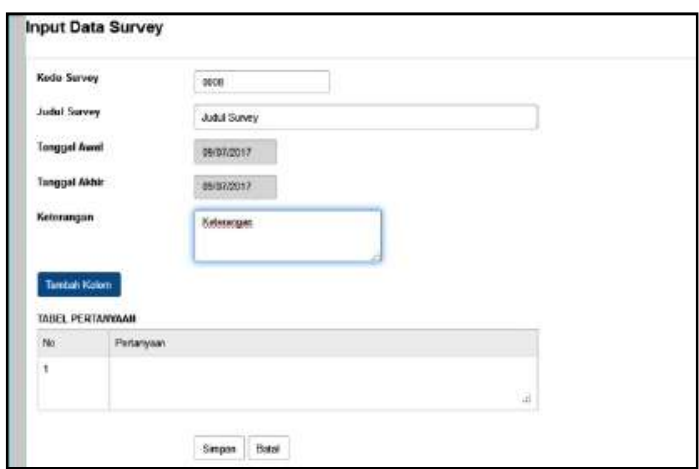

Gambar 20. Halaman Input Data Survey

Pada form input data survey ini, wajib untuk mengisi seluruh kolom teks. Untuk menambah soal/pertanyaan survey klik tombol Tambah Kolom. Untuk menyimpan data survey klik tombol Simpan. Lalu untuk membatalkan proses klik tombol Batal.

Pada halaman edit data survey ini, semua kolom wajib diisi kecuali kolom teks password, hal ini dimaksudkan apabila pengguna tidak ingin mengubah password yang lama. Untuk menyimpan data klik tombol Simpan. Untuk menghapus data survey dapat dengan mengklik tombol (hapus). Lalu untuk membatalkan 
I N F O R M A T I A Jurnal Informatika, Manajemen dan Komputer, Vol. 8 No. 2 , Desember 2016 eISSN : 2580-3042

pISSN : 1979-0694

proses klik tombol Batal. Berikut gambar halaman edit data survey:

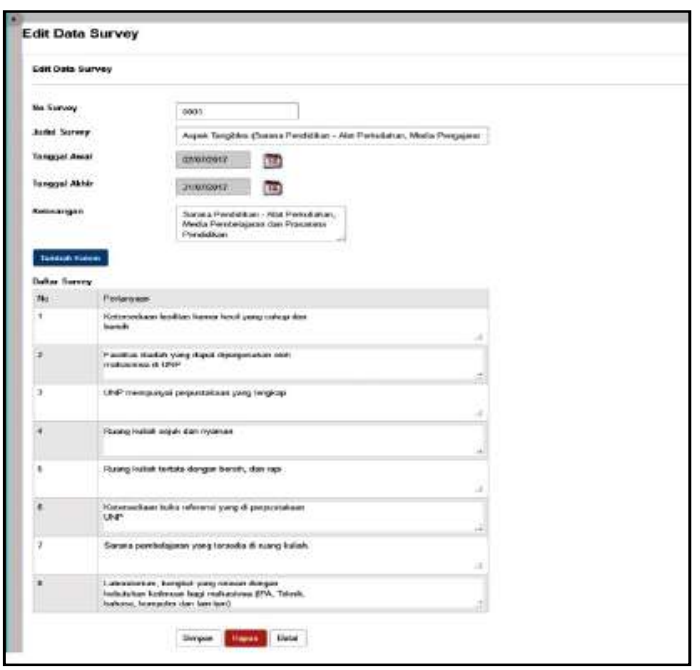

Gambar 21. Halaman Edit Data Survey

\section{Informasi}

Pada submenu informasi ini, admin dapat melihat siapa saja mahasiswa yang telah melakukan pengisian survey di aplikasi e-survey.

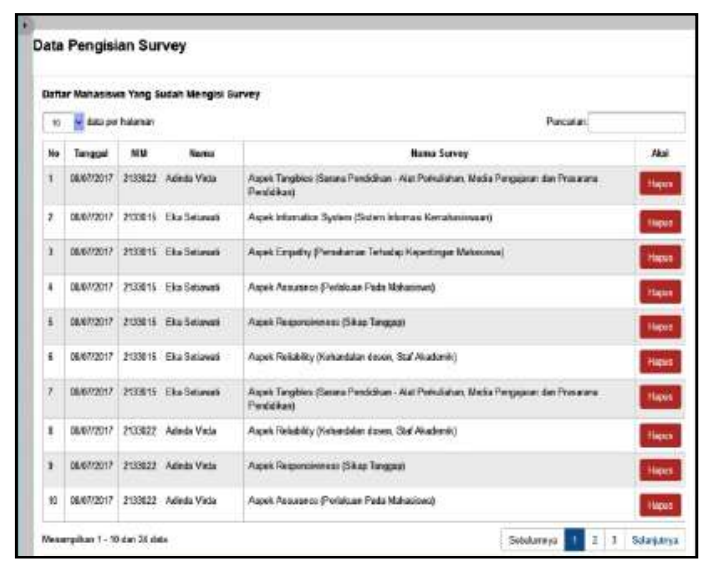

Gambar 22. Halaman Informasi Pengisian Survey

Untuk menghapus data pengisian survey ini dapat dengan mengklik tombol (hapus).

\section{Laporan Mahasiswa}

Submenu ini akan menampilkan laporan mahasiswa

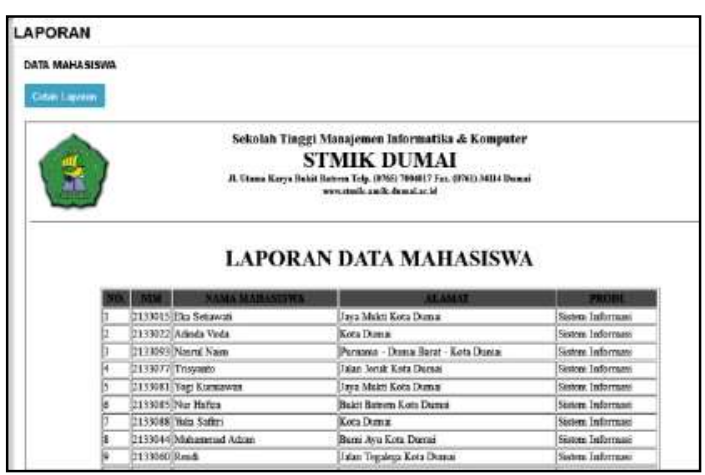

Gambar 23. Laporan Data Mahasiswa

\section{Laporan Survey}

Submenu ini akan menampilkan laporan survey

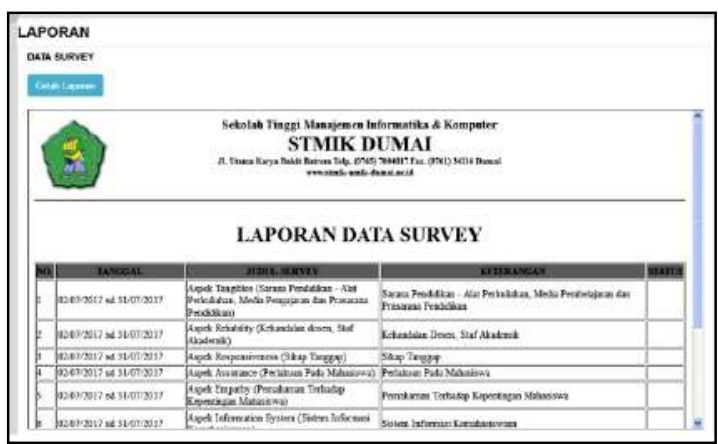

Gambar 24. Laporan Data Survey

\section{Laporan Pengisian Survey}

Submenu ini akan menampilkan laporan pengisian survey. Pilih nama survey dan masukkan tanggal untuk mengurut sesuai tanggal kemudian klik tombol Cari. Untuk mencetak laporan pengisian survey klik tombol Cetak Laporan.

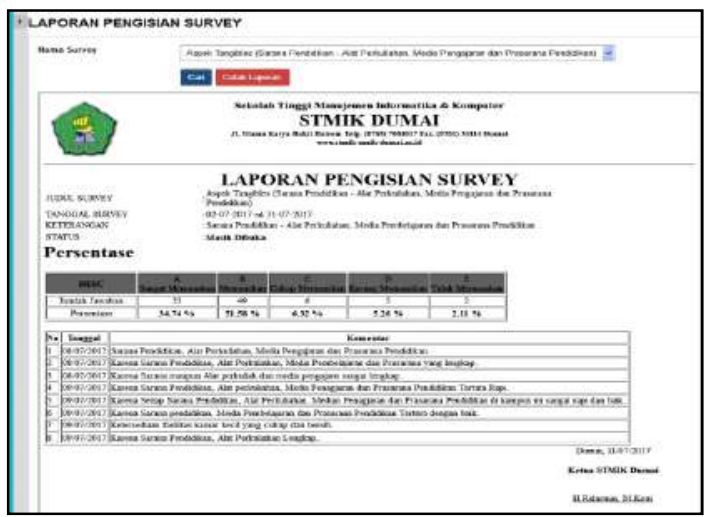

Gambar 25. Laporan Pengisian Survey 
I N F O R M A T I A Jurnal Informatika, Manajemen dan Komputer, Vol. 8 No. 2 , Desember 2016 eISSN : 2580-3042

pISSN : 1979-0694

\section{Laporan Hasil Survey}

Submenu ini akan menampilkan laporan hasil survey yang didalamnya terdapat grafik dan persentase. Pilih nama survey kemudian klik tombol Cari. Untuk mencetak laporan hasil survey klik tombol Cetak Laporan.

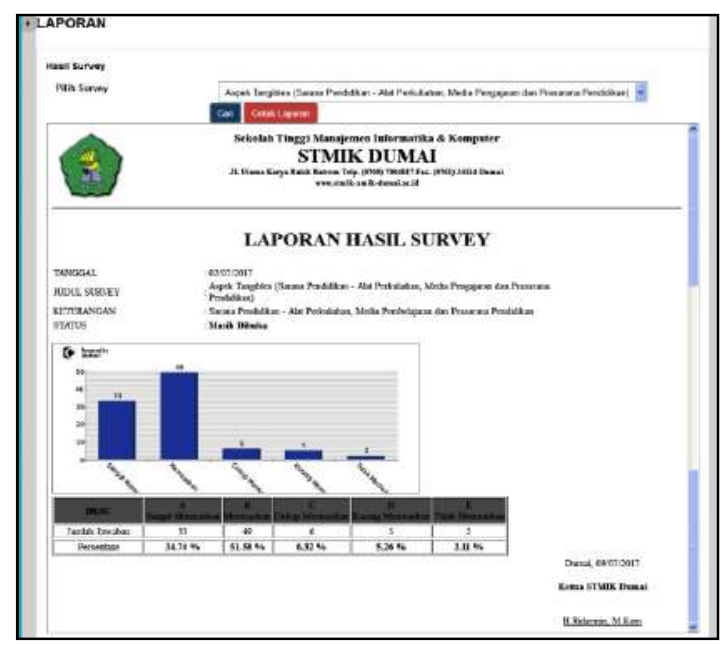

Gambar 26. Laporan Hasil Survey

\section{Dosen}

Tampilan halaman dosen secara keseluruhan tampak sama. Namun, pada menu navigasi yang ada di aplikasi E-Survey tidak sama dengan menu navigasi untuk administrator. Dosen hanya bisa melakukan update profil, pengaturan password, akses pengisian survey (namun dosen tidak dapat menghapus data pengisian survey) dan melihat laporan mahasiswa, laporan survey, laporan pengisian survey, dan laporan hasil survey.

Berikut tampilan update profil dan pengaturan password untuk pengguna dosen :

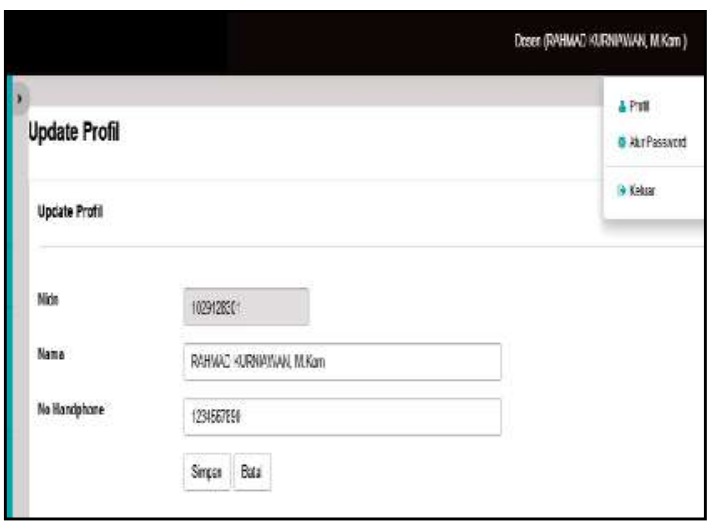

Gambar 27. Pengaturan Update Profil Dosen

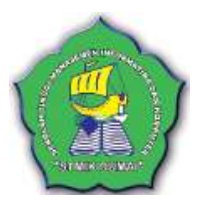

Mahasiswa

Setelah login, maka keluar tampilan halaman utama sebagai berikut :

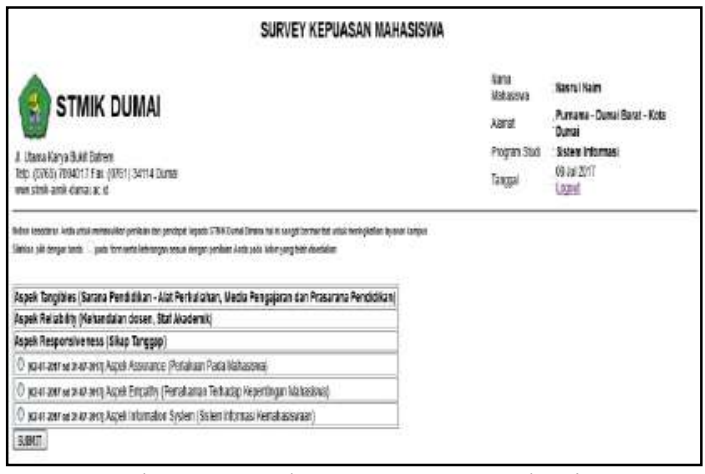

Gambar 28. Halaman Utama Mahasiswa

Pada gambar dapat dilihat, beberapa survey yang harus dikerjakan. Survey ditampilkan berdasarkan range tanggal tertentu. Jika tanggal telah melewati batas waktu pengisian, maka survey tidak di tampilkan.

Untuk mengisi survey ceklis survey, dan klik tombol Submit. Setelah itu akan tampil halaman pertanyaan-pertanyaan survey yang harus dijawab oleh mahasiswa seperti gambar berikut :

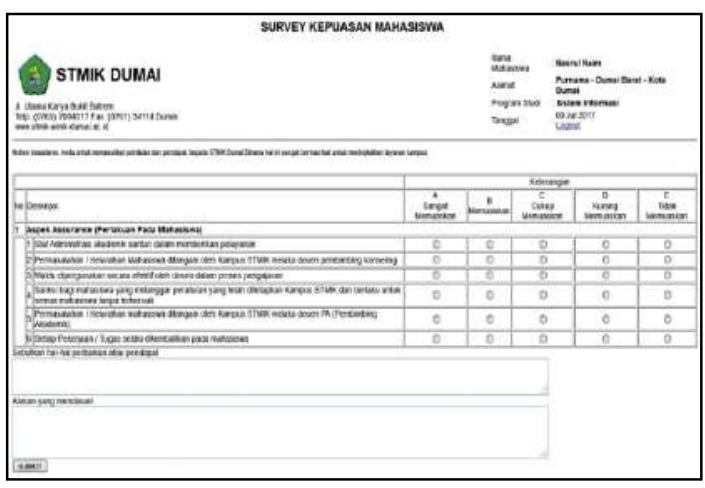

Gambar 29. Halaman Pengisian Survey

Mahasiswa memberi jawaban A, B, C, D, atau $\mathrm{D}$ dan mengisikan pendapat atau hal-hal perbaikan kepada admin atau kampus.

\section{KESIMPULAN}

Berdasarkan hasil pembahasan yang telah diuraikan pada bab-bab sebelumnya, dapat diambil kesimpulan sebagai berikut : 
1. Dengan adanya Sistem Aplikasi ESurvey Berbasis Website pada STMIK Dumai, maka survey dapat dilakukan secara terkomputerisasi dan online untuk mengetahui kepuasaan mahasiswa terhadap pelayanan kampus STMIK Dumai.

2. Dengan menggunakan Sistem Aplikasi E-Survey Berbasis Website pada STMIK Dumai, maka hasil survey dapat diproses dengan cepat dan akurat.

3. Dengan adanya Aplikasi E-Survey Berbasis Web pada STMIK Dumai, maka dapat memberikan kemudahan kepada mahasiswa untuk melakukan penilaian terhadap kinerja dosen dan pelayanan kampus.

\section{REFERENSI}

Abdul Kadir. (2009). Membuat Aplikasi Web dengan PHP dan Database MySQL. CV. Andi Offset. Yogyakarta.

Adnan Mahdi \& Mujahidin. (2014). Panduan Penelitian Praktis untuk Menyusun Skripsi, Tesis \& Disertasi. CV. Alfabeta. Bandung.

Andrea Adelheid \& Khairil Nst. (2012). Buku Pintar Menguasai PHP MySQL. PT. Trans Media. Jakarta Selatan.

Andri Kristanto. (2008). Perancangan Sistem Informasi dan Aplikasinya. Gava Media. Yogyakarta.

Ema Utami dan Anggit Dwi Hartanto. (2012). Sistem Basis Data Menggunakan Microsoft SQL Server 2005. CV. Andi Offset. Yogyakarta.

Hanif al Fatta. (2007). Analisis dan Perancangan Sistem Informasi

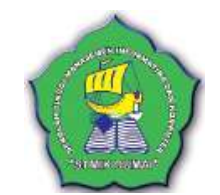

untuk Keunggulan Bersaing Perusahaan dan Organisasi Modern. CV. Andi Offet. Yogyakarta.

Ignas. (2014). Panduan Aplikasi \& Solusi (PAS) Sistem Infomasi Penjualan Online untuk Tugas Akhir. CV. Andi Offet. Yogyakarta.

Jogiyanto HM (2005). Analisa \& Desain Sistem Informasi. CV. Andi Offset. Yogyakarta.

Kendall. (2015). Analisis dan Perancangan Sistem. PT. INDEKS Kelompok GRAMEDIA. Jakarta.

Rahmat Hidayat. (2010). Cara Praktis Membangun Website Gratis. PT. Elex Media Komputindo. Jakarta.

Sofian Effendi, dkk (2012). Metode Penelitian Survei. Jakarta. LP3ES.

Tata Sutabri. (2014). Pengantar Teknologi Informasi. CV. Andi Offset. Yogyakarta. 